\title{
Representações Sociais da velhice LGBT: estudo comparativo entre universitários de Direito, Pedagogia e Psicologia
}

\author{
Old age LGBT social representations: A comparative study \\ conducted with university students from law, pedagogy and \\ psychology programs
}

\section{(1) PSiCOGENTE EISSN 2027-212X}

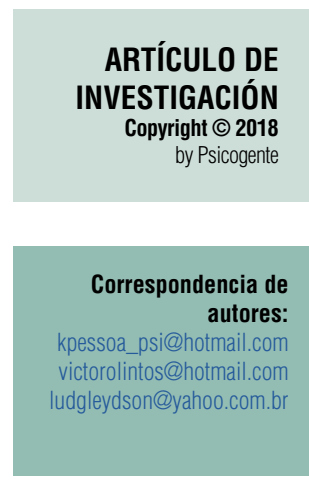

Recibido: 22-04-17 Aceptado: 25-07-17 Publicado: 01-07-18

\section{Representaciones Sociales de la vejez LGBT: estudio comparativo entre los estudiantes universitarios del Derecho, Pedagogía y Psicología}

Resumo

Objetivo: O presente estudo foi realizado com 300 universitários brasileiros dos cursos de psicologia, direito e pedagogia de uma instituição de ensino superior privada no estado do Piauí, Brasil. Objetivou-se com esta pesquisa conhecer as representações sociais destes três grupos de estudantes acerca do envelhecimento LGBT.

Método: Para conhecer tais representações sociais utilizou-se entrevista semi-estruturada e questionário sócio-demográfico para avaliar se há variação das representações de acordo com idade, sexo, graduação e orientação sexual. A amostragem foi por conveniência, sendo que os instrumentos de coleta de dados foram aplicados coletivamente na própria instituição durante o horário de aula. Para a análise dos dados obtidos utilizou-se o software Iramuteq que gerou o dendograma estudado.

Resultados: Entre as principais conclusões observa-se que os integrantes da pesquisaobjetivaram suas RS sobre velhice LGBT em dois campos antagônicos, de um lado revelando o preconceito e a discriminação sofrida pelos idosos, e consequente exclusão social. Por outro o direito que tu tens de viver seu estilo de vida sendo respeitados e assumindo seus direitos e deveres como cidadãos.

Conclusión: Finalmente, percebe-se que a representação social dos universitários sobre a orientação sexual dos idosos está relacionada a uma escolha e não uma construção social. Espera-se que os dados encontrados subsidiem estudos em outros contextos e intervenções psicossociais.

Palavras chave: velhice, lgbt, representações sociais.

Resumen

Objetivo: El presente estudio fue realizado con 300 universitarios brasileños de los cursos de psicología, derecho y pedagogía de una institución de enseñanza superior privada en el estado de Piauí, Brasil. Con este se buscó conocer las representaciones sociales de estos tres grupos de estudiantes acerca del envejecimiento LGBT.

Método: Para conocer tales representaciones sociales se utilizó una entrevista semi-estructurada y un cuestionario sociodemográfico para evaluar si hay variación de las representaciones de acuerdo con edad, sexo, graduación y orientación sexual. El muestreo fue por conveniencia, en tanto que los instrumentos de recolección de datos fueron aplicados colectivamente en la propia institución durante el horario de clase. Para el análisis de los datos obtenidos, se utilizó el software Iramuteq que generó el dendograma estudiado.

Cómo citar este artículo (APA):

Teixeira Carlos, K. P., de Oliveira Santos, J. V., \& Fernandes de Araujo, L. (2018). Representações Sociais da velhice LGBT: estudo comparativo entre

universitários de Direito, Pedagogia e Psicologia. Psicogente 21(40), 297-320. https://doi.org/10.17081/psico.21.40.3076 
Resultados: Entre las principales conclusiones se observa que los participantes de la investigación objetivaron sus RS sobre vejez LGBT en dos campos antagónicos; por un lado, revelando el prejuicio y la discriminación sufrida por los ancianos, y consecuente exclusión social. Por otro, el derecho que tienen a vivir su estilo de vida, siendo respetados y asumiendo sus derechos y deberes como ciudadanos.

Conclusión: Finalmente, se percibe que la representación social de los universitarios sobre la orientación sexual de los ancianos se relaciona con una elección y no con una construcción social. Se espera que los datos encontrados subsidien estudios en otros contextos e intervenciones psicosociales.

Palabras clave: vejez, lgbt, representaciones sociales.

Abstract

Objective: 300 psychology, law and pedagogy students from a Brazilian higher education institution (Estado de Piauí, Brazil) were sampled to conduct this study. This research aims to know students' social representation in relation with LGBT aging.

Method: In order to know such social representations and a semi-structured interview and a socio-demographic questionnaire to evaluate if there are represtantions variations according to age, sex, graduation and sexual orientation were used. The sampling procedure was for convenience; the instruments for data collection were applied in the above institution during class time collectively. For data analysis, the Iramuteq software, which generated the studied dendograma was used.

Results: Among the main conclusions, the members of this research objectivized their RS on old age LGBT in two antagonistic fields, as follows: on the one hand, prejudice and discrimination suffered by elderly and consequent social exclusion is revealed and on the other hand, the right that they have to live their style of Life being respected and assuming their rights and duties as citizens was observed.

Conclusion: As a conclusion, students' social representations in relation with elderly sexual orientation which responds to a choice but not a social construction. It is expected that with the data found studies in other contexts and psychosocial interventions be subsidized.

Keywords: elderly people, lgbt, social representations.

\section{INTRODUÇÃO}

As investigações acerca do envelhecimento durante muito tempo foram escassas, a baixa expectativa de vida era o fator principal que acarretava neste esquecimento da velhice como objeto de estudo, principalmente sob a ótica psicossocial (Fechine \& Trompieri, 2012). Entende-se como velhice, o processo natural e indivisível de mudanças físicas, psicológicas e sociais, que sobremaneira, situa-se conforme a redução de algumas habilidades adquiridas no curso de vida, destarte, as formas de envelhecer são múltiplas e esta fase não deve ser associada à patologia.

Segundo a Organização Mundial de Saúde (2015), são consideradas idosas, as pessoas acima de 60 anos nos países subdesenvolvidos e 65 anos, nos países desenvolvidos. Em seu último relatório sobre envelhecimento e saúde, a OMS (2015) relata que pela primeira vez na história, a maioria das pessoas tem oportunidade de viver até os 60 anos ou mais. No Brasil, de acordo com o Instituto Brasileiro de Geografia e Estatística (2015), a população idosa compreende cerca de 23.5 milhões de pessoas. 
Nas últimas décadas o aumento da população idosa tem causado mudança na pirâmide etária em todo o mundo, agregado a isto, a Gerontologia tem avançado em problematizar os diversos impasses sociais que se fazem presente na sociedade (Araújo, Cruz, \& Rocha, 2013). Os preconceitos, estigmas, mitos e tabus acerca da velhice que durante muito tempo são transmitidos de geração para geração, encontram-se em constante questionamento pela ciência e muitos deles estão sendo desmistificados (Neri, 2014).

Dentre os tabus presentes na sociedade, a sexualidade em inúmeros casos é tratada como algo ausente na velhice, contraditório a isso, os profissionais da gerontologia apresentam que a velhice sexualmente ativa é fundamental para um envelhecimento bem-sucedido. A sexualidade compreende bem mais que o ato sexual, tratando-se então de uma energia que move a afetividade, companheirismo e o prazer, inferindo nas ações sentimentais e relacionais que são foco do bem-estar físico e psicológico (Vieira, Miranda, \& Coutinho, 2012).

Alguns estudos documentam que a sexualidade continua da mesma forma na velhice, o que ocorre são mudanças físicas e psicológicas que influenciam na não aceitação de tais mudanças por parte dos idosos e com isto, reagem negativamente a adaptação do fenômeno sexual nesta fase da vida (Taylor \& Gosney, 2011). Neste sentido, o maior problema da sexualidade não é só biológico, mas também social, em que os idosos não têm informação e convivem repreendidos pelo preconceito (Bernardo \& Cortina, 2012). Quanto aos problemas biológicos que afetam o desempenho sexual, pode-se citar a disfunção erétil nos homens e a redução da lubrificação vaginal feminina, e em alguns casos, os efeitos colaterais devido à medicamentos (Guerra \& Caldas, 2010).

A sexualidade é uma temática ainda negligenciada no processo de envelhecimento, ainda mais quando é atrelada a pessoas homoafetivas, fazendo com que as manifestações de preconceito em relação ao público LGBT, tornem escassas as discussões englobando a velhice como uma fase vivenciada por lésbicas, gays, bissexuais, travestis e transexuais (Araújo, 2016). Atenta-se ao fato de que as pessoas homoafetivas são as que mais presenciam situações de preconceito, seja sutil ou explícito, em qualquer espaço da sociedade, principalmente nas redes sociais (Junqueira, 2012).

Tendo em vista, este panorama de homofobia e ageísmo, torna-se complexo a percepção destes fenômenos entrelaçados, que por sua vez, vem acarretando 
em estigmas sociais da velhice LGBT, afinal, estes idosos estão alcançando tal fase do desenvolvimento e construindo novos legados, mas vivem à margem da discriminação. Isto é, no século XXI, o aumento da presença de pessoas LGBT tem trazido repercussão nas discussões sobre gênero e preconceito.

Atualmente, é possível encontrar informações e discussões que dizem respeito às questões sexuais, físicas e psicológicas das pessoas LGBT em sites e blogs de ONGs ou ativistas, porém pouco se discute sobre esse público envelhecido. As pesquisas que discutem sobre essa temática ressaltam sempre o preconceito sofrido pelos idosos LGBT. Leal e Mendes (2017) discutem sobre a invisibilidade e o silêncio quando trata-se de velhice e homossexualidade, buscando conhecer como esses sujeitos enfrentam o envelhecimento e a perspectiva de institucionalização (Leal \& Mendes, 2017). Tarquino et al., (2015) tratam sobre a atenção a saúde da população LGBT idosa e destacam que a qualidade da vida sexual desde público é comprometida tanto pela falta de informação bem como pela maneira preconceituosa que os profissionais e a sociedade em geral encaram a sexualidade do idoso (Tarquino et al., 2015).

O livro organizado por (Orel \& Fruhauf, 2015) apresenta vários aspectos sobre a velhice LGBT, desde os culturais, familiares e individuais, perpassando pela saúde e bem-estar destes idosos, discutindo o estigma e a velhice e sobre as idosas transgêneros (Orel \& Fruhauf, 2015). Mesmo nos estudos da Gerontologia, quando as experiências de envelhecimento vão de encontro às regras heteronormativas, estas tendem ao esquecimento (Debert \& Henning, 2015; Santos, Carlos, Araújo, \& Negreiros, 2017). Henning (2017), apresenta em seu estudo um olhar antropológico e crítico sobre as principais tendências, polêmicas e embates teóricos sobre o que tem sido chamado de "gerontologia LGBT", bem como seus desdobramentos como constituição, legitimação e criação de políticas públicas (Henning, 2017).

As variações de expressão da sexualidade do idoso, incluídas as que se relacionam com o curso da vida, e determinadas proposições sobre os significados sociais e subjetivos da sexualidade são um campo fértil para estudos, tanto no que se refere a como os idosos LGBT se percebem quanto, sobre o conhecimento elaborado e participado da sociedade sobre homossexualidade na velhice.

Neste sentido, o presente estudo utilizou-se como suporte teórico-metodológico a teoria das Representações Sociais (RS), que permite uma maior compreensão sobre o estudo da velhice LGBT. A RS surge da necessidade de tornar algo que é estranho em algo familiar (Jacques et al., 2014). Esta teoria busca compreender os atores sociais em sua totalidade, sendo, portanto 
uma abordagem psicossocial, que busca entender as inter-relações entre os sujeitos, os fenômenos e o contexto que estão inseridos (Moscovici, 2007; Sêga, 2000). Moscovici (2007) reconhece a RS como o conjunto de crenças, conceitos e explicações que surgem no cotidiano permitindo reproduzir um novo dado, objeto ou um acontecimento, enfatiza que tais representações surgem no meio social e se modificam de acordo com o tempo, e gradualmente, evocam novas representações.

Atualmente, o referencial da teoria das RS tem sido muito utilizado nos estudos das ciências sociais, visto que contribui para a compreensão do pensamento e das práticas sociais (Torres, 2015). A representação é o processo que se estabelece entre o mundo e as coisas, é um saber prático (Jodelet, 2001; Sêga, 2000). Surge da necessidade de saber o que se entende do mundo que nos cerca, é compreender, interpretar e tomar uma posição frente a determinado assunto, conduzindo as comunicações sociais, advindas dos processos de assimilação dos conhecimentos, no desenvolvimento individual e coletivo (Jodelet, 2001). É importante ressaltar que as RS não são opiniões individualizadas, elas garantem uma visão unificada e coerente do contexto a qual fazem parte.

A partir do questionamento que foi analisado nesta pesquisa, "¿Como o senhor (a) entende a velhice LGBT?", buscou-se conhecer junto aos universitários, os significados compartilhados de suas representações construídas sobre o idoso LGBT na sua interação social. A pesquisa procurou compreender os pensamentos, sentimentos, percepções e experiências de vida compartilhadas pelos universitários, levando-se em consideração o curso de graduação a que estão vinculados.

Destaca-se que as RS da velhice não heteronormativa, construídas e compartilhadas socialmente, constituem-se como um fator importante de estudo e de compreensão dos idosos LGBT, pois intervêm no processo de conscientização da população, garantias de direitos e qualidade de vida destes idosos, uma vez que provocam diferentes concepções sobre a questão.

Diante do exposto, este artigo tem como objetivo principal verificar e comparar as RS de três grupos de estudantes universitários dos cursos de direito, psicologia e pedagogia acerca da velhice LGBT, buscando compreender a diversidade de contextos que se entrelaçam e que são vivenciadas pelas mais diversas pessoas de diferentes idades e perfis. 


\section{MÉTODO}

\subsection{Diseño}

Trata-se de um estudo descritivo-exploratório, com dados transversais e por conveniência.

\subsection{Participantes}

Contou-se com a participação de 300 universitários brasileiros, escolhidos de forma não probabilística, intencional e acidental (sendo 100 do curso de direito, 100 do curso de psicologia e 100 do curso de pedagogia) de uma Instituição de Ensino Privada da cidade de Teresina, Piauí (Brasil), de ambos os sexos com idades entre 21 e 57 anos, com média de idade de 28.56 anos ( $D P=8.59)$, sendo que a maioria são mulheres, reconhecem-se da cor parda, são solteiros, de religião católica.

Faz-se necessário mencionar que tal escolha ocorreu com o intuito de comparar as RS acerca da velhice LGBT entre os universitários de direito, psicologia e pedagogia, considerando-se que as diferenças entre grupos podem colaborar para a construção de RS distintas. Como critério de inclusão da amostra utilizou-se alunos a partir do quinto período dos referidos cursos, pois se acredita que os mesmos já tenham adquirido um aparato teórico e prático suficiente para possibilitar a reflexão proposta por este estudo baseados nos pilares norteadores do curso. Os participantes deveriam estar regularmente matriculados na Instituição de Ensino, ter livre escolha para participar ou não da pesquisa, podendo desistir a qualquer momento e por fim sua participação deu-se de forma voluntária e anônima.

\subsection{Instrumento}

O roteiro de entrevista, utilizado nos três grupos de universitários pesquisados, contemplou em sua primeira parte dados sociodemográficos que teve a finalidade de fazer um levantamento dos sujeitos da pesquisa, como por exemplo obter informações sobre idade, sexo, estado civil, etnia, renda, orientação sexual, religião, curso que está se graduando, se tem algum parentesco com algum individuo com orientação sexual homossexual e se convive com algum idoso LGBT. Em sua segunda parte, a questão norteadora: O que o (a) Senhor (a) sabe sobre a velhice LGBT? Vale ressaltar que esta questão foi elaborada tendo por base os objetivos da presente pesquisa. 


\subsubsection{Coleta de dados da entrevista}

A coleta dos dados ocorreu no âmbito da instituição de ensino dos entrevistados, tendo em vista a facilidade de encontrá-los visto que já se deslocavam para a IES para assistir aula. A aplicação dos instrumentos se deu de forma coletiva, em sala de aula com a autorização do coordenador do curso e do professor, bem como de forma individual em outros espaços da instituição, levando em média 40 minutos para o seu preenchimento.

No primeiro momento, aos discentes participantes foi apresentado o Termo de Consentimento Livre Esclarecido (TCLE), que continha as informações sobre a pesquisa e as implicações que a participação do aluno acarretava, o qual foi lido e assinado por cada um dos participantes e pelo pesquisador responsável antes dos entrevistados responderem aos instrumentos. Os alunos também foram informados sobre as questões do sigilo, risco e benefícios da pesquisa, sobre o livre arbítrio em participar ou não e até mesmo desistir de sua participação a qualquer momento sem nenhum prejuízo. Um único pesquisador aplicou os instrumentos, informando sobre os objetivos da pesquisa e fornecendo as instruções para o correto preenchimento dos mesmos.

\subsection{Procedimentos e considerações éticas}

Inicialmente o projeto de pesquisa foi enviado para avaliação do Comitê de Ética e Pesquisa (CEP), orientado pelas diretrizes e normas regulamentadoras de pesquisa nas Ciências Humanas e Sociais envolvendo seres humanos no contexto brasileiro, de acordo com a Resolução no 510/2016 do Conselho Nacional de Saúde, recebendo parecer de aprovação para realização da pesquisa.

Após a aprovação foi contatada a Instituição de Ensino Superior privada onde a pesquisa foi realizada, para solicitar autorização para início da coleta de dados. A composição da amostra se deu de forma não probabilística, sendo aplicados os instrumentos em todos os alunos que se dispuseram a participar da pesquisa até atingir o número máximo de participantes por curso.

\subsection{Análise dos dados}

Para análise dos dados obtidos através da entrevista, utilizou-se o software gratuito IRAMUTEQ, que permite fazer análises estatísticas de dados textuais e sobre tabelas indivíduos/palavras (Camargo \& Justo, 2013). Desse modo, 
foi elaborado1 banco de dados em formato de bloco de notas (formato que o programa suporta), de maneira que cada resposta foi associada a uma linha de comando, fazendo assim uma alusão do texto ao participante.

As linhas de comando apresentam os dados sóciodemográficos dos entrevistados, separando cada dado por asteriscos, indicando o participante (n), o sexo, a idade, a graduação e a orientação sexual.

Cada entrevista é composta por conteúdos semânticos, que formaram o banco de dados ou corpus analisado pelo Iramuteq. Foi realizada uma Análise Hierárquica Descendente, que permite a formação de classes de segmentos de textos que, ao tempo em que apresentam vocabulário semelhante entre si, diferem dos segmentos de texto das outras classes (Camargo \& Justo, 2013). Por fim, com os dados obtidos com a aplicação do questionário sóciodemografico foram submetidos a estatísticas descritivas, como média, percentil e desvio padrão no software SPSS na sua versão 22.

\subsection{Conflito de Interesses}

Não houve conflito de interesse entre os pesquisadores, já que todos objetivavam conhecer as RS de universitários sobre o envelhecimento LGBT, e os participantes também corroboraram com a relevância da pesquisa.

\section{RESULTADOS}

A análise dos resultados do dendograma constituído pelo corpus de 300 unidades de contexto inicial ( $\mathrm{UCls}$ ), conseguidos mediante as respostas à pergunta ¿O que o (a) Senhor (a) sabe sobre a velhice LGBT? Refere-se à representação dos universitários sobre o idoso LGBT, apresentou uma divisão de corpus em 283 UCEs (Unidades de Contexto Elementar), em que 1419 palavras, que ocorreram 7565 vezes, sendo $87.35 \%$ consideradas na classificação hierárquica descendente. 


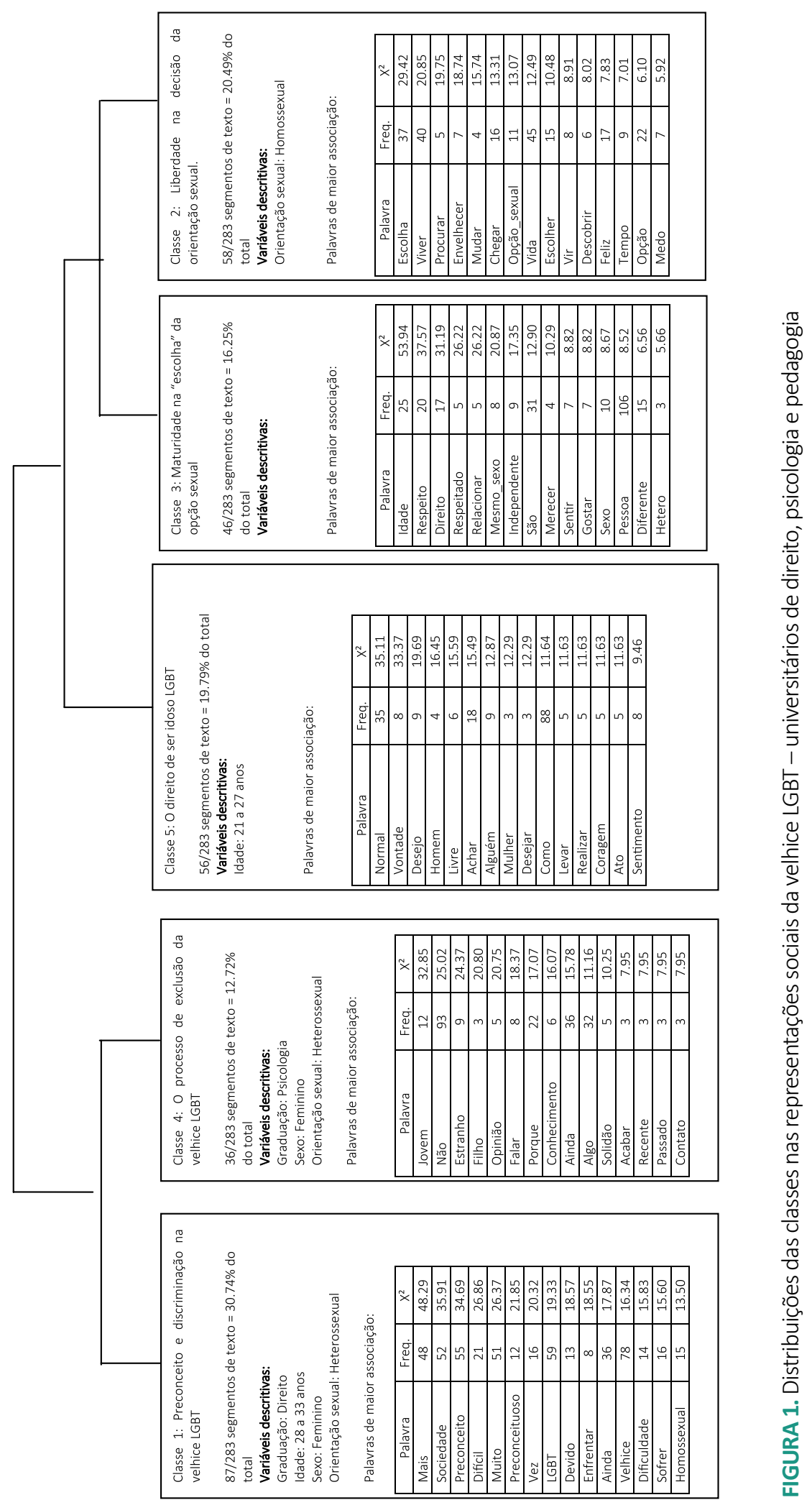


No dendograma (ver Figura 1) pode-se observar que o corpus de dividiu em cinco classes, com o título e a descrição de cada uma delas, o número de UCEs, ou segmento de textos, que a compõe, as variáveis descritivas e as palavras com maior associação com a classe relatada, considerando o coeficiente alcançadono teste de associação qui-quadrado $\left(\mathrm{X}^{2}\right)$.

Ressalta-se que a RS dos universitários sobre a velhice LGBT estão estruturadas em dois campos representacionais antagônicos, subdivididos em 5 classes. 0 primeiro campo corresponde às Vivências de preconceito e exclusão, que foi construído pelas classes 1 intitulada Preconceito e discriminação na velhice LGBT e classe 40 processo de exclusão da velhice LGBT. No que diz respeito ao segundo campo, este está relacionado à Liberdade e direito de vivenciar a velhice $L G B T$ composto pelas classes 2 com título Liberdade na decisão da orientação sexual, classe 3 nominada de Maturidade na "escolha" da opção sexual e classe 5 designada de $O$ direito de ser idoso LGBT. Serão discutidas através das UCEs as classes estruturadas a seguir.

\subsection{Vivências de preconceito e exclusão (Classes 1 e 4)}

O campo de vivências de preconceito apresenta tanto os estigmas vivenciados por estes idosos bem como a intolerância social face a experiência LGBTdos velhos, e a exclusão se faz presente por receio de sofrer discriminação ao assumir publicamente sua condição.

\subsubsection{Classe 1: Preconceito e discriminação na velhice LGBT}

Os conteúdos que compõem as RS do preconceito e discriminação de acordo com as entrevistas estão permeados de estigmas sociais, incluindo a dificuldade de aceitação da família, intolerância religiosa, anormalidade. Para estes estudantes, a velhice é vista como uma fase que demanda cuidada, fragilidade e dependência. Essa primeira representação exibe um alto poder explicativo através de sua representatividade na análise semântica, é composta por 87 UCEs que apresenta representatividade de $30.74 \%$, tornando-se relevante quanto às representações encontradas.

Nesta classe percebe-se a predominância do preconceito e discriminação, e levando-se em consideração as variáveis descritivas, pode-se caracterizá-la como uma classe constituída majoritariamente por universitários do sexo feminino com idades entre 28 e 33 anos. As palavras que obtiveram maior associação com a classe foram: sociedade, preconceito, difícil, muito, preconceituoso, enfrentar, dificuldade, sofrer, homossexual. Em seu conteúdo, ser 
idoso LGBT é um indivíduo que sofre duplo preconceito, sendo muitas vezes de forma explícita e violenta, sendo compreendida até mesmo como doença, conforme relatos a seguir:

"Acho como uma doença hormonal e psicológica" (Participante 44, graduando de direito e heterossexual).

"Se trata de algo vergonhoso" (Participante 56, graduando de direito, heterossexual).

"Uma sociedade que deve ter o dobro de respeito devido o preconceito já sofrido, combinado com a idade avançada, assim sofrendo preconceito em duplo grau" (Participante 93, graduando de direito, heterossexual).

"A velhice LGBT na contemporaneidade ainda é vista sob muita discriminação, porém entendo como uma forma de a pessoa manifestar sua individualidade, sua maneira de ser e estar no mundo embora essa manifestação ainda não seja aceita e compreendida pela maior parte das pessoas, surgindo assim a intolerância e conseqüentemente a violência". (Participante 123, graduando de psicologia, heterossexual)

"Falar sobre LGBT na velhice ainda parece estranho logo vista que estas pessoas um dia foram jovens que viviam sob um regime educacional tradicional, patriarcal onde tudo que fugisse aos padrões sociais era mal visto. Esta é a herança que carregamos do preconceito, portanto é uma velhice ainda incomum". (Participante 276 , graduando de pedagogia, heterossexual)

Essa patologização e criminalização da identidade de gênero limitam a agencia dos indivíduos LGBT na tomada de decisões (Fredriksen-Goldsen et. al., 2015). Os relatos apresentam com freqüência uma alusão ao medo ou receio que os idosos LGBT tem em assumir sua sexualidade para a família e grupo de amigos, tanto por receio da não aceitação como por causa da intolerância religiosa. Desta maneira, estudos apontam para o estabelecimento de vínculos com outros homossexuais e com pessoas que aceitem incondicionalmente sua realidade homoafetiva (Marques \& Sousa, 2016) como uma forma encontrada por estes idosos para trabalhar sua auto-aceitação.

"Deve ser doloroso, pois há muito preconceito, ainda mais sendo idoso, deve receber muitas acusações vindo da própria família. Porém na minha opinião, não devemos ter preconceito nem 
maltratarmos nosso próximo, mas esta e uma prática abominada por Deus, pois na Bíblia está escrito que estes não herdarão o Reino dos Céus, creio na salvação e torço para que qualquer pessoa LGBT, independente de sua idade se converta e se arrependa de seu pecado". (Participante 116, graduando de psicologia, heterossexual)

"Eu tenho preconceito sim e não concordo com isso, pois eu acho que a família sofre muita exposição e pela vergonha, mas isso vai depender também muito das famílias, também se for famílias conservadoras afeta muito mais". (Participante 129, graduando de psicologia, heterossexual)

Outro fato que merece destaque nessa classe refere-se à ocorrência do preconceito por entenderem que os idosos LGBT encontram-se em uma fase que demanda maior cuidados por apresentarem mais fragilidade e necessidade de cuidados e por não possuírem parceiros fixos. Percebe-se que a estabilidade financeira é ponto crucial para a sua aceitação social.

"Penso que não deve ser fácil, principalmente no aspecto do LGBT não ter um parceiro fixo. A sociedade já e muito preconceituosa e o idoso por si só já merece uma atenção especial". (Participante 116, graduando em psicologia, heterossexual)

"Entendo que é um processo difícil de ser encarado, pois nossa sociedade e muito discriminatória, fazendo com que essa pessoa idosa se sinta a margem, por diversas razões, uma delas seria seu próprio sustento e cuidados compativeis com a idade, uma vez que na velhice a pessoa se torna mais vulnerável". (Participante 160. graduando em psicologia, heterossexual)

"De certa forma vejo ainda com muita dificuldade, pois a nossa sociedade é muito preconceituosa, rotula, aponta e exclui. Porém o homossexual pode sofrer mais ainda na velhice, pois se ele não for independente, realizado financeiramente, poderá ficar jogado no mundo, sem direito e respeito". (Participante 183, graduando de psicologia, heterossexual)

É fundamental entender a construção da identidade LGBT ao longo da vida, englobando as relações familiares em todas as fases do desenvolvimento. É importante a implementação de políticas públicas que possam influenciar nos aspectos culturais, familiares e individuais da velhice LGBT, perpassando desde a saúde, ao trabalho, bem-estar, e aos estigmas sofridos, para assim 
poder promoveras mudanças culturais e sociais tão necessárias, diminuindo assim o preconceito e discriminação.

Verifica-se dessa forma na classe 1 que os conteúdos da análise hierárquica tornam perceptível os estereótipos negativos da sociedade frente a velhice LGBT. A qualidade da vida sexual do idoso é comprometida devido à falta de informação e o preconceito da sociedade. O idoso é cada vez mais inferiorizado devido regras e normas sociais que definem que as pessoas envelhecidas são excluídas da sexualidade. A ligação direta com a classe 4 remete a reflexão sobre o receio que os idosos homossexuais têm de assumir sua sexualidade por medo de rejeição ou perseguição.

\subsubsection{Classe 4: O processo de exclusão da velhice LGBT}

De acordo com os 36 UCEs que estruturam esta classe, com representatividade de $12.72 \%$ do total, salienta-se que a mesma é considerada a classe com menor poder explicativo deste dendograma entre os 300 estudantes pesquisados. No referente às variáveis descritivas a classe 4 foi formada por discentes de psicologia, do sexo feminino e orientação heterossexual.

Verifica-se uma preponderância de conteúdos relacionados à solidão, exclusão e carência, em razão das palavras que tiveram maior associação com a classe: jovem, estranho, filho, opinião, falar, conhecimento, solidão, acabar, passado, contato. Os conteúdos lexicais mencionados pelos universitários dizem respeito à exclusão, ressaltando as atitudes discriminatórias aos idosos e LGBT, como pode ser evidenciado nos discursos a seguir:

"Acredito que a maioria das pessoas na velhice LGBT sejam solitárias, sem muito afeto por parte de algumas pessoas, pois ainda existe muito preconceito em relação a esta escolha". (Participante 105, graduando de psicologia, heterossexual)

"Algo ainda muito complexo, porque ainda não é muito visto $e$ nem falado. É como se os LGBT quando ficam velhos fossem se escondendo, se omitindo, porque é muito difícil se ver casais LGBT idosos". (Participante 111, graduando de psicologia, heterossexual)

"Ser idoso já é difícil e bastante excluído, muitas vezes até pelos próprios familiares e quando se trata de LGBT aí é uma situação crítica de discriminação, preconceito, abandono e muitas vezes também isolados do seu meio social". (Participante 191, graduando de psicologia, heterossexual) 
Esses dados podem ser observados de forma consonante com a literatura quando observase os relatos descritos sobre abandono e omissão. A sociedade em muitos casos reproduz a idéia de que o indivíduo só é valorizado se estiver agindo segundo as regras a ele impostas. O exercício de reconhecer o outro que não partilha dos atributos que possuímos, depende do lugar que ocupamos (Louro, 2010). A partir daí a sociedade constrói demarcadores que representam a "norma" (que estão em consonância com os padrões estipulados culturalmente) e os que ficam "fora dela", à margem. Quando se classifica os indivíduos, a sociedade produz rótulos. Sem perceber, os indivíduos se enquadram a padrões ditados socialmente, que Henning (2017) discute como panorama heteronormativo, ao discutir sobre gênero e sexualidade. Esses padrões são limitadores, que por sua vez se forem negados geram opressão e exclusão, bem como se tornam naturalizados.

Outro ponto que merece destaque nesta classe é a relação que os estudantes fazem entre a velhice LGBT e a perda de sentido da vida, sendo justificada devido à ausência de parceiros e conseqüentemente a não procriação. Faz-se necessário ressaltar que da mesma forma que outras classe sociais adotam determinados estilos de vida, os idosos LGBT também se identificam com grupos que investem em determinadas características sociais e culturais, e aqui destaca-se a necessidade de criação de espaços de homossociabilidade visto que além dos poucos lugares direcionados para esse público, sofrem o estigma da invisibilidade, pois não são percebidos por sua identidade sexual nos espaços públicos.

"Como algo estranho pois a maioria delas, como o caso do meu tio, teve a opção de não ter filhos e por isso quando chegam na velhice acabam se sentindo muito só, sem falar nos parentes que tem preconceito com o mesmo" (Participante 53, graduando de direito, heterossexual).

"Acredito que se não tiver um parceiro ou parceira onde possa dividir as coisas boas da vida como um casal hetero, não deve ter muito sentido na vida" (Participante 175, graduando de psicologia, heterossexual).

"Entendo que seja um momento na maioria dos casos, que a pessoa tenha passado por todas as fases desde a aceitação a solidão, pois ainda acho a questão do alto índice de infidelidade é uma barreira entre os LGBT para que possam ter uma velhice agradável com o companheiro que escolheu. Através de relatos compartilhados, acredito que a solidão ainda seja o que mais acompanha os LGBT 
na velhice, independente de terem filhos ou não. Solidão no sentido de estar só e não necessariamente a auto-realização" (Participante 185 , graduando de psicologia heterossexual).

"Provavelmente perigosa. Muitas implicações podem ocorrer como, por exemplo, a solidão que já e própria da velhice de qualquer pessoa em muitos casos. Há possivelmente uma maior possibilidade de abandono do idoso LGBT até mesmo por Ihe faltar muitas vezes, desde novo, a estrutura familiar. Já que ele escolheu pessoa do mesmo sexo, nunca poderá procriar e ter sua prole, aumentando assim o risco de solidão e abandono na velhice" (Participante 192, graduando de psicologia, heterossexual)

"Sem vida, pois já viveram tudo que tinha de viver" (Participante 223, graduando de pedagogia, heterossexual).

A insistente invisibilidade que essa categoria sofre, deságua na vitimização subjetiva e o isolamento do velho LGBT, devido o caráter transitório de suas relações, a supervalorização da juventude e o desligamento da família de origem, que é substituída por amigos ou pessoas que os aceitem incondicionalmente. Ressaltam-se alguns avanços nas conquistas de políticas públicas voltadas para a diversidade. Revela-se uma transformação na sociedade brasileira quanto a uniões homoafetivas, é crescente o número de casamentos homoafetivos, segundo (Meletti \& Scorsolini-Comin, 2015) há mais de 60 mil casais homossexuais no Brasil e a adoção de filhos por esses casais vem crescendo gradativamente e foi impulsionada pela aprovação da união civil entre pessoas do mesmo sexo. Embora a doção por casais homoafetivos não ter sido aprovada ainda no Brasil, já se encontra exemplos de abertura em diversas regiões do pais.

\subsection{Liberdade e direito de viver a velhice Igbt (Classes 2, 3, 5)}

\subsubsection{Classe 2: Liberdade na decisão da orientação sexual}

A segunda classe da análise hierárquica aqui aplicada foi estruturada com 58 UCEs, representando $20.49 \%$ do total de 300 entrevistas. As palavras que obtiveram maior associação com a classe referem-se à liberdade na decisão da orientação sexual, conforme descritas a seguir: escolha, viver, procurar, envelhecer, mudar, opção sexual, vida, descobrir, feliz, tempo, opção, medo. Nesta classe, os conteúdos semânticos mais característicos são:

"A liberdade de opção e realização de seus desejos" (Participante

94, graduação em direito, heterossexual). 


\section{"Mera decisão de cunho sexual diante a vontade de realizartal desejo} sexual" (Participante 84, graduando de direito, heterossexual).

A partir dos dados obtidos, percebe-se que a sociedade produz uma idéia de que os idosos LGBT estão em busca somente de satisfação de desejos sexuais. Dessa forma desconsideram a necessidade que os idosos LGBT possam vir a ter de afeto, amor, companheirismo. A sexualidade não se resume somente ao ato sexual em si, trata-se de um misto de prazer, cumplicidade e amor entre duas pessoas, como forma de conhecimento de seu corpo e do outro, não abrange somente as questões fisiológicas, ela é concebida como um elemento que dá sentido e significado à existência humana (Fernandez \& Paniagua, 2007). Diante do exposto, se faz necessários esclarecimentos à classe universitária das diversas formas de experiênciar a sexualidade da velhice LGBT, que pode ser demonstrada muitas vezes por gestos e atitudes.

Pode-se verificar também, nessa classe, que os universitários compreendem que os idosos homossexuais, apesar buscarem vivenciar sua sexualidade livremente, têm receio de assumir sua condição por medo de rejeição ou perseguição, conforme citações abaixo:

"São idosos que na maioria das vezes passaram a vida escondendo seus sentimentos, sua orientação sexual, ou por conta do contexto que vive ou mesmo por medo do preconceito ou discriminação. Hoje, não que eles não sofram preconceitos, mas a liberdade de expressão melhorou e muitos estão assumindo sua homossexualidade" (Participante 251, graduando em pedagogia, heterossexual). "É complicado explicar, porém vejo que essas pessoas têm uma experiência muito grandiosa de vida, acredito que tiveram que enfrentar vários desafios para conquistar sua liberdade de viver com dignidade devido essa sociedade preconceituosa em que vivemos" (Participante 182, graduando de psicologia, heterossexual).

Sendo assim, fica claro que a RS dos universitários sobre os idosos LGBT é que são sujeitos que sabem o que querem, que já conquistaram algum espaço na sociedade, ainda que pequeno, e devido a isso tem uma maior liberdade para poder expressar seus sentimentos, porém ainda permeados de medo devido ao preconceito. 


\subsubsection{Classe 3: Maturidade na "escolha" da opção sexual}

A classe 3 da análise hierárquicaque foi utilizada está diretamente relacionada com a classe acima descrita (classe 2 ) e envolveu $16.25 \%$ do total, resultando em 46 unidades de contexto elementar. As palavras que tiveram maior associação com a classe foram: idade, respeito, direito, relacionar, mesmo sexo, independente, merecer, sentir, gostar. Pode-se perceber, conforme as UCEs, as características desta fase de acordo com os conteúdos semânticos a seguir:

"Como forma de aprendizagem, ultrapassando vários tipos de situações difíceis decorrentes do dia a dia, mas sempre juntos enfrentando todos os obstáculos". (Participante 70, graduando de direito, heterossexual)

"Acredito que seja algo tranqüilo de se lidar, pois os idosos já devem ter passado por varias situações, situações essas que acredito que os deixaram bastante maduros e seguros para aprender a lidar com as críticas e com isso abstrair apenas o que há de bom nas pessoas". (Participante 106, graduando de psicologia, heterossexual).

"Pessoas com maturidade suficiente para assumirem o que são de forma segura, sem preocupação com o que os outros dizem". (Participante 193, graduando de pedagogia, heterossexual)

As RS nessa classe estruturam-se em torno da opção sexual, ancoradas aprendizagem devido às experiências vivenciadas, de superação de barreiras. Desta forma, é fundamental conhecer os momentos históricos vivenciados e os papeis sociais desempenhados, pois fatores culturais e atributos pessoais influenciam no envelhecimento e essas construções individuais influenciam no bem-estar, relacionamento social e familiar (Fredriksen-Goldsen et al., 2015; Orel \& Fruhauf, 2015).

Um ponto bastante relevante que deve ser discutido nessa classe é a representação da homossexualidade com uma "escolha", como algo que depende da vontade e decisão do sujeito. Por outro lado, compreender a velhice LGBT como uma fase de auto-aceitação, de sabedoria e segurança para lidar com as críticas, conforme falas a seguir:

"Como algo muito bem resolvido e por entender que o mundo atual é difícil, assumir que se tem atração, desejo e vontade por pessoas do mesmo sexo, quanto mais na velhice, é um ato de coragem, pois a sociedade tem uma visão do idoso como alguém correto, 
que segue regras e normas perante a sociedade e não os vê como alguém que ainda tem desejos e vontades a serem explorados no próprio corpo. Respeito a coragem, pois a maioria foram educados para entenderem que homem foi feito para a mulher". (Participante 121, graduação psicologia, heterossexual)

"Ainda é um pouco estranho devido o preconceito, mas é visto com mais aceitação. São pessoas mais conscientes de suas escolhas e mais experientes, então encaram a vida com mais sabedoria. LGBT também são pessoas com sentimentos $e$ independente de sua idade, tem direito de fazer suas próprias escolhas". (Participante 146 , graduando de psicologia, heterossexual)

"Nunca pensei no assunto, mas analisando neste momento, entendo como uma consolidação de uma escolha feita na idade jovem e que persiste pelo resto da vida". (Participante 177, graduando de psicologia, heterossexual)

"Como uma aceitação do que ela realmente é, pois através das experiências vividas pela mesma, tem acapacidade de sereconhecer, identificar e se aceitar como ela realmente se reconhece, alem de viver de forma plena". (Participante 180, graduando de psicologia, heterossexual)

Desta forma, se faz necessário compreender que a experiência homossexual é considerada como uma construção social e não uma escolha como muitos tendem a defini-la. De acordo com (Mota, 2014), é uma ação consciente do sujeito no seu espaço social, que ele o faz através de lembranças, sentimentos, atividades, sociabilidades e práticas sexuais em uma sociedade onde o jovem, o individual e a norma heterossexual são valorizados. Não é inerente ao indivíduo visto que ela é construída, modificada e transformada com base nas experiências sociossexuais e afetivas do sujeito no curso da vida.

\subsubsection{Classe 5: O direito de ser idoso LGBT}

Por último, a quinta classe da análise hierárquica descendente empregada envolve $19.79 \%$ do total das entrevistas, concluindo 56 UCEs. A variável descritiva que predomina nessa classe, os universitários com idade entre 21 e 27 anos. A RS nessa classe organiza-se em torno do direito que o idoso LGBT tem de viver o seu estilo de vida com respeito e dignidade, tendo as palavras mais freqüentes a seguir: normal, vontade, desejo/desejar, livre, 
levar, realizar, coragem, ato, sentimento. Pode-se perceber, conforme as UCEs, nos conteúdos semânticos a seguir:

"Entendo que seja normal, assim como os heterossexuais. Um humano como outro qualquer, que tem amor e que em decorrência do tempo envelheceu, e que com certeza não teve como correr de sua realidade, pois é natural e não uma escolha. O amor não tem face nem corpo físico, então não tem como definir que amor só existe entre heteros". (Participante 66, graduando de direito, homossexual)

"Entendo como um fenômeno normal, pois eles ou elas também são dignos de respeito e têm direitos e deveres na sociedade. $A$ velhice LGBT é uma dignidade prevista na CF 88, pois todos nós somos iguais, devemos respeitar e amar o próximo". (Participante 72, graduando de direito, orientação não informada)

"São pessoas com opção sexual diferente da que a sociedade tem como padrão, mas que merecem todos os seus direitos, porque são pessoas humanas com sua dignidade e merecem respeito como qualquer ser humano". (Participante 221, graduando de pedagogia, heterossexual)

Nesse agrupamento, pode-se verificar que as RS foram objetivadas nos aspectos referentes à importância do respeito, do amor, dos direitos e deveres como cidadãos. Todavia, os idosos LGBT seguem tendo grandes dificuldades de participação e representação na vida social e no exercício da cidadania, neste sentido, percebe-se uma inclinação social a discutir muito mais o conceito de velhice, em detrimento dos direitos das pessoas idosas (Araújo, 2016; Araújo \& Fernández-Rouco, 2016). Assim, se faz necessário desenvolver na população em geral a capacidade de compreender os aspectos biopsicossociais do envelhecimento e desenvolver nos idosos LGBT a capacidade de superar adversidades, a resiliência, de modo que enfrentar as dificuldades inerentes ao processo do envelhecimento LGBT (Orel \& Fruhauf, 2015).

Observa-se também que é muito freqüente na representação dos universitários o direito de igualdade em relação aos casais heterossexuais, bem como aos casais homossexuais mais jovens. Ressalta-se que a idade não define gênero e que o aumento do número de pessoas LGBT é um desafio social que deve ser observado e tratado com mais atenção, sendo necessário o desenvolvimento de políticas de inclusão e contra o discurso do ódio, conforme relatos a seguir: 
"Uma nova realidade, eu acredito que isso irá se tornar algo comum no futuro devido ao grande número de indivíduos LGBT". (Participante 55, graduando de direito, heterossexual)

"Entendo como algo normal e presente. Precisamos aceitar essa modernidade, precisamos incluir os nossos irmãos. Não aceito a visão religiosa que insiste em crucificar quem deseja amar alguém que é seu semelhante. Devíamos lutar contra o ódio, o rancor e não contra inúmeras possibilidades de amor". (Participante 122, graduando de psicologia, heterossexual)

"O idoso LGBT é igual a qualquer outra pessoa nova, não é porque ele está velho que não pode viver sua vida com sua sexualidade escolhida. Está na velhice sendo LGBT é um desafio na sociedade em que vivemos". (Participante 139, graduando de psicologia, heterossexual)

A busca para satisfazer seus desejos, atrai os homossexuais para relacionamentos às escondidas e o expõe a situações de tomada de decisão, sair ou não do "armário", tendo então que assumir um posicionamento frente a heterossexualidade e forçando seu grupo social a aceitá-lo com tolerância. Ao assumir esse posicionamento, os homossexuais afirmam seus direitos frente à heteronormatividade e passam a ter mais espaço nas lutas pela diversidade sexual, cidadania, políticas públicas e direitos humanos (Araújo \& FernándezRouco, 2016; Mota, 2014).

O conjunto de dados desta pesquisa é relevante na medida em que possibilita ter acesso à construção do conhecimento dos universitários que num futuro próximo poderá na atuação profissional lidar com algum idoso LGBT. Constatou-se que as RS são embasadas em estereótipos negativos sobre acerca da velhice LGBT, de modo que estes idosos sofrem preconceitos por dois motivos: idade e orientação sexual.

\section{DISCUSSÕES}

A presente pesquisa versou sobre as RS do envelhecimento LGBT, de forma comparativa entre universitários dos cursos de direito, psicologia e pedagogia de uma Instituição de Ensino Superior Privada na cidade de Teresina, Piauí (Brasil). Os dados obtidos entre os estudantes possibilitaram representações comuns aos três grupos, sem nenhuma particularidade que possa ser destacada em nenhum grupo. 
As informações levantadas revelaram que os integrantes desta investigação objetivaram suas RS da velhice LGBT em dois campos antagônicos, de um lado revelando o preconceito e discriminação sofridos por estes idosos e conseqüentemente a exclusão social e por outro lado reafirmam o direito que os velhos LGBT têm de viver seu estilo de vida sendo respeitados e assumindo os seus direitos e deveres de cidadãos.

Pode-se destacar a presença do preconceito e discriminação na maioria das falas dos estudantes, sendo muitas vezes de uma forma direta e em algumas de forma discreta, bem como nas falas de apoio ao idoso LGBT, fazendo alusão ao direito de serem felizes, porém enfrentam dificuldades por conta dos estigmas. Outro ponto de destaque na maioria das entrevistas é a alusão ao termo "escolha da orientação sexual", demonstrando assim que a RS dos universitários pesquisados sobre a homossexualidade esta relacionada a uma escolha e não a uma construção social.

A partir das entrevistas analisadas, percebeu-se um grande desafio para o idoso LGBT, visto que a velhice já é estigmatizada por si só, e quando atada a homossexualidade, sofrem duplo estigma, o agravo da idade e a sexualidade desviante. Neste sentido, revelam a evidência do preconceito, em que nas RS da população a velhice LGBT reflete solidão, dificuldade e mitos que perpetuam na sociedade. Portanto, pode-se afirmar que a relação entre idade e sexualidade ainda tem muito a ser discutido, percebe-se que está ocorrendo uma mudança de paradigma, mas ainda distante do ideal esperado para que os idosos LGBT possam vivenciar a velhice de forma tranquila.

Por último, este estudo possui algumas limitações. Em primeiro lugar devido às especificidades regionais socioculturais não se pode generalizar tais dados para outros contextos. Em segundo lugar, sugerem-se pesquisas futuras com amostras populacionais que possam servir de subsídios para intervenções psicossociais com escopo de atenuar os preconceitos e estereótipos negativos em relação a velhice LGBT.

Nota de Autores:

Representações sociais da velhice LGBT: estudo comparativo entre universitários de direito, pedagogia e psicologia.

\section{REFERÊNCIAS}

Araújo, L. F. (2016). Aspectos Psicossociais da Velhice LGBT. Psicologia em Estudo, 21(2), 359-361. http://dx.doi.org/10.4025/psicolestud.v21i2.28739 
Araújo, L. F., Cruz, E. A. \& Rocha, R. A. (2013). Representações sociais da violência na velhice: estudo comparativo entre profissionais de saúde e agentes comunitários de saúde. Revista Psicologia \& Sociedade, 25(1), 203-212. http://dx.doi. org/10.1590/S0102-71822013000100022

Araújo, L. F. \& Fernandéz-Rouco, N. (2016). Idosos LGBT: Fatores de Risco e Proteção. In: D. V. S., Falcão; L. F. Araújo; J. S. Pedroso. (Orgs). Velhices: Temas Emergentes nos Contextos Sociofamiliar, de Saúde Mental, Cuidado e Violência. (pp. 22-32). 1ed. Campinas-SP: Editora Alínea. Disponible em http://www.grupoatomoealinea.com.br/velhices-temas-emergentes-nos-contextos-psicossocial-e-familiar. html

Bernardo, R. \& Cortina, I. (2012). Sexualidade na Terceira Idade. Revista Enfermagem UNISA, São Paulo, 13(74-8), 1-12. Disponible em http://www.portalterceiraidade. com.br/dialogo_aberto/sexualidade_3i/index.htm

Camargo, B. V. \& Justo, A. M. (2013). IRAMUTEQ: Um software gratuito para análise de dados textuais. Temas em Psicologia, 21(2), 513-518. http://dx.doi.org/10.9788/ TP2013.2-16

Debert, G. \& Brigeiro, M. (2012). Fronteiras de gênero e a sexualidade na velhice. Revista Brasileira de Ciências Sociais, 27(80), 37-54. http://dx.doi.org/10.9788/ TP2013.2-16

Debert, G. G. \& Henning, C. E. (2015). Velhice, gênero e sexualidade: revisando debates e apresentando tendências contemporâneas. Mais 60 - Estudos sobre Envelhecimento, 6(63), 8-31. http://dx.doi.org/10.9788/TP2013.2-16

Fechine, B. R. A. \& Trompieri, N. (2012). O processo de envelhecimento: as principais alterações que acontecem com o idoso com o passar dos anos. InterSciencePlace, 1(20), 106-132. http://dx.doi.org/10.9788/TP2013.2-16

Fernandez, M. L. \& Paniagua, S. C. (2007). La sexualidad en la persona adulta mayor. In Gonzalez, A.C.M.; Brenes, M.R (Orgs.). Envejece La sexualidade? Buenos Aires: Espacio Editorial. Disponible en https://www.researchgate.net/publication/298341113_Sexualidad_y_salud_en_el_adulto_mayor_Libro_La_salud_ de_los_adultos_mayores_Una_vision_compartida

Fredriksen-Goldsen, R. I., Hoy-Ellis, C. P., Muraco, A., Goldsen, J. \& Kim, H. (2015). The health and well-being of LGBT older adults: disparaties, risks, and resilience across the life course. In: Orel, N. A., Fruhauf, C. A. (Orgs.). The lives of LGBT older adults: Understanding challenges and resilience. Washington, DC: American Psychological Association. Disponible en https://www.researchgate.net/profile/Brent Schneider2/publication/308317784_Positive_Factors_Relating_to_the_Health_ and_Well-being_of_Older_LGBTQ_Adults/links/57e0907e08aec6ce9f28ec16/ Positive-Factors-Relating-to-the-Health-and-Well-being-of-Older-LGBTQ-Adults. pdf

Guerra, A. C. L. C. \& Caldas, C. P. (2010). Dificuldades e recompensas no processo de envelhecimento: a percepção do sujeito idoso. Ciência \& Saúde Coletiva, 15(6), 2931-2940. http://dx.doi.org/10.1590/S1413-81232010000600031

Henning, C. E. (2017). Gerontologia LGBT: velhice, gênero, sexualidade e a constituição dos "idosos LGBT". Horizontes Antropológicos, 1(47), 283-323. https:// horizontes.revues.org/1513

Instituto Brasileiro de Geografia Estatística. (2015). Pesquisa Nacional por Amostra de Domicílios: síntese de indicadores 2014. Coordenação de Trabalho e Rendimento. Rio de Janeiro: IBGE. Disponible em http://biblioteca.ibge.gov.br/visualizacao/ livros/liv94935.pdf

Jacques, M. D. G. C., Strey, M. N., Bernardes, N. M. G., Guareschi, P. A., Carlos, S. A. \& Fonseca, T. M. G. (2014). Psicologia social contemporânea: livro-texto. Petropólis: 
Editora Vozes. Disponible em https://www.saraiva.com.br/psicologia-social-contemporanea-livro-texto-459912.html

Jodelet, D. (2001). Representações sociais: um domínio em expansão. Rio de Janeiro: EdUERJ. Disponible em https://es.scribd.com/document/180768696/JODELET-um-dominio-em-expansao

Junqueira, R. D. (2012). Homofobia: limites e possibilidades de um conceito em meio a disputas. Bagoas-Estudos gays: gêneros e sexualidades, 1(01), 1-22. http:// dx.doi.org/10.9788/TP2013.2-16

Leal, M. D. G. S. \& Mendes, M. R. O. (2017). A Geração duplamente silenciosa-velhice e homossexualidade. Revista Portal de Divulgação, 1(51), 18-35. http://dx.doi. org/10.9788/TP2013.2-16

Louro, G. (2010). O corpo educado: pedagogias da sexualidade. Belo Horizonte: Autêntica Editora. Disponible em https://repositorio.ufsc.br/bitstream/ handle/123456789/1230/Guacira-Lopes-Louro-O-Corpo-Educado-pdf-rev. pdf?sequence $=1$

Marques, F. D. \& Sousa, L. (2016). Portuguese older gay men: Pathwaysto Family Integrity. Revista Paidéia, 26(64), 149-159. Disponible en http://www.scielo.br/ scielo.php?pid=S0103-863X2016000200149\&script=sci_arttext

Meletti, A. T. \& Scorsolini-Comin, F. (2015). Conjugalidade e expectativas em relação à parentalidade em casais homossexuais. Psicologia: teoria e prática, 17(1), 37-49. http://dx.doi.org/10.15348/1980-6906/psicologia.v17n1p37-49

Moscovici, S. (2007). Representações Sociais: investigações em Psicologia Social. Petrópolis: Vozes. Disponible en http://revistascientificas.ifrj.edu.br:8080/ revista/index.php/reci/article/view/69/87

Mota, M. P. (2014). Ao sair do armário entrei na velhice...: homossexualidade masculina e o curso de vida. Rio de Janeiro: Mobile. Disponible em https:// produto.mercadolivre.com.br/MLB-805621507-livro-ao-sair-do-armario-entrei-na-velhice-gay-gls-_JM

Neri, A. L. (2014). Palavras-chave em gerontologia. Brasil:Alínea.Disponible em https:// www.saraiva.com.br/palavras-chave-em-gerontologia-4-ed-2014-8314515.html

OMS - ORGANIZAÇÃO MUNDIAL DA SAÚDE. (2015). Relatório Mundial de Envelhecimento e Saúde. Genebra: OMS, 2015. Disponível em: http://sbgg.org.br/ wp-content/uploads/2015/10/OMS-ENVELHECIMENTO-2015-port.pdf

Orel, N. A. \& Fruhauf, C. A. (2015). The intersection of culture, family, and individual aspects: A guiding model for LGBT older adults. Washington, DC: American Psychological Association. https://doi.org/10.1080/1550428X.2015.1071953

Santos, J. V. O., Carlos, K. P. T., Araújo, L. F. \& Negreiros, F. (2017). Compreendendo a velhice LGBT: uma revisão da literatura. In: L. F. Araújo; C. M. R. G. Carvalho. (Org.). Envelhecimento e Práticas Gerontológicas (pp. 81-96). 1ed. Curitiba-PR/Teresina-PI: Editora CRV/EDUFPI. Disponible http://www.redalyc.org/service/redalyc/ downloadPdf/4595/459553539006/Velhice+LGBT:+uma+an\%E1lise+das+representa\%E7\%F5es+sociais+entre+idosos+brasileiros/7 http://www.redalyc.org/ service/redalyc/downloadPdf/4595/459553539006/Velhice+LGBT:+uma+an\%E1 lise+das+representa\%E7\%F5es+sociais+entre+idosos+brasileiros/7

Sêga, R. A. (2000). O conceito de representação social nas obras de Denise Jodelet e Serge Moscovici. Anos 90, 8(13), 128-133. http://dx.doi.org/10.9788/TP2013.2-16

Taylor, A. \& Gosney, M. A. (2011). Sexuality in older age: essential considerations for healthcare professionals. Age and Ageing, 40(5), 538-543. http://dx.doi. org/10.9788/TP2013.2-16 
Tarquino, M. L., Santos, L. V., Coutinho, M. I. B., Cruz, L. H. L. \& Brasil, M. L. (2015). Invisibilidade na assistência: um enfoque na atenção à saúde da população LGBT idosa. Anais CIEH, Campina Grande, 2(1), 1-4. Disponible em http://www. editorarealize.com.br/revistas/cieh/trabalhos/TRABALHO_EV040_MD4_SA9_ ID290_26072015175127.pdf

Torres, T. L., Camargo, B. V., Boulsfield, A. B. \& Silva, A. O. (2015). Representações sociais e crenças normativas sobre envelhecimento. Revista Ciência \& Saúde Coletiva, 20(12), 3621-3630. http://dx.doi.org/10.9788/TP2013.2-16

Vieira, K. F. L., Miranda, R. S. \& Coutinho, M. P. L. (2012). Sexualidade na Velhice: Um Estudo de Representações Sociais. Psicologia e Saber social, 1(1), 120-128. http:// dx.doi.org/10.9788/TP2013.2-16

Esta obra está bajo: Creative commons attribution 4.0 international license. El beneficiario de la licencia tiene el derecho de copiar, distribuir, exhibir y representar la obra y hacer obras derivadas siempre y cuando reconozca y cite la obra de la forma especificada por el autor o el licenciante.

\section{(cc) BY}

